\title{
How does cultural capital affect educational performance: Signals or skills?
}

\section{Asta Breinholt ${ }^{1}$ (D) | Mads Meier Jæger ${ }^{2}$ (D)}

\author{
${ }^{1}$ The Institute for Social \\ Research, University of Michigan, Ann \\ Arbor, Michigan, USA \\ ${ }^{2}$ Department of Sociology, University of \\ Copenhagen, Copenhagen, Denmark

\section{Correspondence} \\ Asta Breinholt, The Institute for Social \\ Research, University of Michigan, 426 \\ Thompson St, Ann Arbor, MI 48106-1248, \\ USA. \\ Email: lunda@umich.edu

\section{Funding information} \\ The European Research Council under \\ the European Union's Seventh Framework \\ Programme [FP/2007-2013], Grant/Award \\ Number: ERC grant 312906.
}

\begin{abstract}
In this paper, we test two mechanisms through which cultural capital might affect educational performance: (a) teachers misinterpreting cultural capital as signals of academic brilliance and (b) cultural capital fostering skills in children that enhance educational performance. We analyse data from the ECLS-K and ECLS-K:2011 from the United States and focus on three aspects of children's cultural capital: participation in performing arts, reading interest and participation in athletics and clubs. We find that (1) none of the three aspects of cultural capital that we consider affects teachers' evaluations of children's academic skills; (2) reading interest has a direct positive effect on educational performance; and (3) the direct effect of reading interest on educational performance does not depend on schooling context. Our results provide little support for the hypothesis that cultural capital operates via signals about academic brilliance. Instead, they suggest that cultural capital fosters skills in children that enhance educational performance. We discuss the theoretical implications of our findings.

\section{KEYWORDS}

cultural capital, educational success, teacher bias, schooling context, non-cognitive skills
\end{abstract}




\section{1 | INTRODUCTION}

Social stratification research documents persisting inequalities in educational success across countries and over time. French sociologist Pierre Bourdieu famously argued that these inequalities arise in part from individuals' and families' differential possession of cultural capital, that is, familiarity with high-status culture and the ability to express this familiarity effortlessly (Bourdieu, 2006; Bourdieu \& Passeron, 1977). Two interpretations of how cultural capital operates exist. The first interpretation, emphasized by Bourdieu, is that cultural capital sends signals of academic brilliance to teachers, which in turn lead to favoritism, preferential treatment, and to educational success. In this interpretation, children's cultural capital does not reflect their actual academic ability but needs a catalyst, the teacher, to be converted into educational success (DiMaggio, 1982; Jæger \& Breen, 2016; Kalmijn \& Kraaykamp, 1996; Roscigno \& Ainsworth-Darnell, 1999; Wildhagen, 2009). The second interpretation, which can be inferred from Bourdieu, and which has been developed in recent research, is that cultural capital fosters skills in children, for example analytical competence and creativity, that directly enhance educational success (Kaufman \& Gabler, 2004; Kisida, Greene, \& Bowen, 2014; Lareau, 2011, Sullivan, 2007). In this interpretation, cultural capital affects educational success directly and does not need a catalyst to operate.

In this paper, we empirically test the two interpretations that cultural capital affects educational success by (a) sending signals of academic brilliance to teachers, and (b) fostering skills in children. We focus on three aspects of cultural capital-familiarity with legitimate culture, reading interest, and communicative and social skills-and build on an existing literature that finds positive correlations between these aspects of children's cultural capital and different measures of educational success, for example test scores, grades, and final educational attainment (e.g., Bodovski, 2010; Bodovski \& Farkas, 2008; Cheadle, 2008, 2009; Covay \& Carbonaro, 2010; DiMaggio, 1982; Gaddis, 2013; Sullivan, 2001). While this literature shows that cultural capital has a positive direct effect on educational success, it does not distinguish the two mechanisms outlined above through which cultural capital might operate. Some research has demonstrated that a positive association exists between children's cultural capital and teachers' evaluations of children's academic skills and behaviors (Bodovski \& Farkas, 2008; Dumais, 2006a, 2006b; Farkas, 2018; Farkas, Sheehan, Grobe, \& Shuan, 1990; Kozlowski, 2015; Takei, Johnson, \& Clark, 1998). Consistent with Bourdieu, this research suggests that cultural capital sends signals of academic brilliance to teachers, who in turn form upwardly biased perceptions of children. However, with the exception of two studies (Roscigno \& Ainsworth-Darnell, 1999; Wildhagen, 2009), this literature has not linked teacher evaluations to children's actual educational success. In this paper, we test the two proposed mechanisms through which cultural capital might affect educational success within a joint framework. In addition, we extend existing research in two ways by employing a particularly robust research design and by exploring if different schooling contexts shape the extent to which cultural capital is converted into educational success.

First, we use a research design that enables us to draw stronger conclusions about causal relationships than previous research (Roscigno \& Ainsworth-Darnell, 1999; Wildhagen, 2009). Specifically, we estimate fixed effects models that control for the fact that children's cultural capital is likely to be correlated with unobserved characteristics that also affect their skills and educational performance (for example, baseline academic ability and motivation). In doing so, we take into account that children who possess more cultural capital send stronger signals of academic brilliance and do better in school for reasons that are substantively different from, but empirically correlated with, their cultural capital (Gaddis, 2013; Jæger \& Breen, 2016). In our empirical analysis, we use panel data from the Early Childhood Longitudinal Study-Kindergarten cohort 1998 (ECLS-K; National Center for Educational Statistics, 2009) and the recently released Kindergarten Class of 2010-2011 (ECLS-K:2011; National Center for Educational Statistics, 2017). These studies, which were carried out in the United States, include longitudinal information on (a) teachers' evaluations of children's academic skills (a proxy for teachers' potentially biased perceptions of children), (b) different aspects of children's cultural capital (participation in performing arts, reading interests and participation in athletics and clubs), and (c) children's educational performance (standardized test scores in reading and math). This means that, in addition to offering a more robust methodological framework 
than previous research, we are able to replicate all analyses using two separate datasets, thereby increasing the external validity of our results (Bloome, 2015; Freedman, 1991).

Second, we analyse if the two mechanisms through which cultural capital might affect educational success (signals vs. skills) work differently in different schooling contexts. Previous research suggests that schooling contexts differ in the extent to which they enable children to convert their cultural capital into educational success (DiMaggio, 1982; Lareau, 2011; Roscigno \& Aisnworth-Darnell, 1999). Building on this research, we hypothesize that if cultural capital operates via signals, schooling contexts in which teachers and students have high socioeconomic status (SES) are more likely to recognize and reward cultural capital compared to schooling contexts in which teachers and students have low SES. Alternatively, we hypothesize that if cultural capital operates mainly via skills, children in low-SES schooling contexts benefit more from their cultural capital than those in high-SES contexts because the skills associated with cultural capital, which might be less prevalent in low-SES contexts, stand out. Empirically, we use information on teachers (e.g., on their education and family background), classrooms (e.g., the proportion of children labeled as gifted) and schools (e.g., their overall socioeconomic composition) to analyze if the effect of cultural capital on educational performance differs across high- and low-SES schooling contexts.

We report three key findings. The first is that, in both datasets, children's reading interests, a key dimension of their cultural capital (de Graaf, de Graaf, \& Kraaykamp, 2000; Sullivan, 2007), has a direct positive effect on educational performance. Two other dimensions of cultural capital-participation in performing arts and participation in athletics and clubs-do not have any effect. The second finding is that none of our indicators of cultural capital has any effect on teachers' evaluation of children's English and math skills. This result is in contrast with the interpretation that cultural capital operates via teachers' biased perceptions of children's academic ability. The third finding is that the direct effect of cultural capital on educational performance is remarkably homogenous across schooling contexts characterized by different teacher, classroom, and school characteristics. Overall, our empirical results challenge the interpretation that cultural capital operates via signals of academic brilliance. Instead, they suggest that cultural capital fosters skills in children that enhance educational performance, and furthermore that this mechanism operates in a similar way across otherwise different schooling contexts.

\section{2 | THEORETICAL FRAMEWORK}

In this section, we present our theoretical framework. Drawing on Bourdieu and on a recent literature on cultural capital, we describe the concept of cultural capital and different mechanisms through which it has been argued to shape educational success. We then address different ways in which the effect of cultural capital on educational success might vary across schooling contexts and present a set of empirical hypotheses.

\section{1 | The concept of cultural capital}

Although there is controversy regarding the definition of cultural capital (Davies \& Rizk, 2017; Lamont \& Lareau, 1988), Bourdieu saw cultural capital as familiarity with the cultural codes, manners, and behaviors that dominate in a particular society (Bourdieu, 1984, 1996; Bourdieu \& Passeron, 1977, 2006). He regarded cultural capital as a valuable resource on par with economic capital (income, wealth, etc.) and social capital (gainful social connections and networks). Similar to economic and social capital, cultural capital can be converted into other forms of capital through exchanges in material and symbolic markets. Bourdieu used the term "cultural capital" in different ways to emphasize its embodied, material, and relational aspects. This means that there is little consensus in the literature on the exact definition of cultural capital. In this paper, we draw on an influential definition of cultural capital, which defines it as "... institutionalized, i.e. widely shared, high-status cultural signals (attitudes, preferences, formal knowledge, behaviours, goals, and credentials) used for social and cultural exclusion" (Lamont \& Lareau, 1988, 
p. 156). We rely on this definition because, similarly with Bourdieu's approach, it emphasizes that cultural capital pertains to signals, skills, and behaviors that can be used to obtain more or other forms of capital. Moreover, this definition does not restrict cultural capital to familiarity with "highbrow" forms of culture and emphasizes that it must be used to yield a return.

\section{2 | Cultural capital and educational success}

According to Bourdieu, the educational system is a subfield within society in which cultural capital carries particular weight (Bourdieu, 2006; Bourdieu \& Passeron, 1977). Although he did not offer a clear account of how cultural capital shapes educational success, subsequent literature building on Bourdieu highlights two mechanisms through which cultural capital might operate.

The first mechanism, emphasized by Bourdieu in several of his writings (e.g., Bourdieu, 1996, 2006; Bourdieu \& Passeron, 1977), is that cultural capital sends signals of academic brilliance (DiMaggio, 1982; Jæger \& Breen, 2016; Kahn, 2012; Kalmijn \& Kraaykamp, 1996; Roscigno \& Ainsworth-Darnell, 1999; Wildhagen, 2009). Cultural capital, as it manifests in children's attitudes, behaviors, and modes of self-presentation, acts as a signaling device that teachers and other institutional gatekeepers misinterpret as academic brilliance. The consequence of this "misrecognition" is that teachers come to favor and give preferential treatment to children who possess cultural capital, which in turn enhances these children's educational success. A key assumption in this interpretation of cultural capital is that cultural capital is fundamentally unproductive because it does not reflect any actual academic skills. This is the case because, as Bourdieu argues, what counts as high-status culture is arbitrary in the sense of not capturing any objective "truth" but rather the idiosyncratic tastes of those who hold power (Bourdieu \& Passeron, 1977, pp. 11-31). It is for this reason that cultural capital needs a "catalyst," the teacher, to be converted into something concrete that promotes educational success, for example favoritism and preferential treatment. In this interpretation, cultural capital affects educational inequality because children from privileged backgrounds tend to possess more cultural capital than those from less privileged backgrounds, which gives them an unfair advantage in the educational system.

The second mechanism is that cultural capital affects educational success by equipping children with skills that help them do well in school. Bourdieu did not articulate this mechanism clearly, but it may be inferred from his writings. For example, in Reproduction he writes that:

through all the skill-learning processes of everyday life, and particularly through the acquisition of the mother tongue ... logical dispositions are mastered in their practical state. These dispositions ... predispose children unequally towards symbolic mastery of the operations implied as much in a mathematical demonstration as in decoding a work of art. (Bourdieu \& Passeron, 1977, p. 43)

Furthermore, in The State Nobility he writes that "a person's relationship to culture and language" is "associated with very real differences in both content and form" (Bourdieu, 1996, p. 22). Both statements would suggest that cultural capital also includes actual skills-for example, knowledge, vocabulary, and verbal proficiency-that enhance educational success. Building on Bourdieu, a recent literature has argued that cultural capital includes a set of skills that promotes educational success. For example, this literature argues that cultural activities such as going to arts and music classes may increase children's analytical skills (Kisida et al., 2014), while extracurricular activities might enhance their intellectual creativity (Kaufman \& Gabler, 2004) and socio-emotional, communicative, and social skills (Lareau, 2011). In addition, it suggests that reading for enjoyment, also an important aspect of cultural capital, might develop academic skills like linguistic fluency and broad cultural knowledge (Sullivan, 2007). In conclusion, this interpretation of cultural capital suggests that, in addition to operating via signals, cultural capital may also enhance educational success via actual skills. Below, we present a research design that enables us to distinguish each mechanism within a joint framework. 


\section{3 | Schooling contexts}

In addition to affecting educational success via the two different mechanisms presented above, in this paper we argue that the effect of cultural capital may depend on the schooling context in which it is applied. Bourdieu did not explicitly address contextual heterogeneity in the effect of cultural capital, but a later literature has argued that SES characteristics of schooling contexts are important for converting cultural capital into educational success (DiMaggio, 1982; Leopold \& Shavit, 2013). We draw on this literature to analyze how the effect of cultural capital on educational success, operating via either signals or skills, might differ across schooling contexts.

First, if cultural capital operates mainly via signals, it may yield a higher return in high-SES schooling contexts than in low-SES ones because, in the former, teachers and peers possess more cultural capital and are more likely to appreciate and reward embodied signals of familiarity with high-status culture (Andersen \& Jæger, 2015; Leopold \& Shavit, 2013). In this context, actual skills associated with cultural capital, for example analytical and creative skills, might matter less because children in high-SES schooling contexts on average possess more skills than those in low-SES contexts. This line of reasoning is consistent with, but adds context to, Bourdieu's argument that cultural capital acts as an "inequality multiplier" that mainly benefits high-SES children.

Second, if cultural capital operates mainly via skills, its effect may be stronger in low-SES schooling contexts than in high-SES ones because, in the former, teachers and peers on average possess less cultural capital and are less inclined to recognize signals of familiarity with high-status culture. Instead, teachers and peers may more easily recognize and reward actual analytical and creative skills associated with cultural capital, which in turn promote educational success. This argument is different from Bourdieu's ideas but are in line with DiMaggio's (1982) cultural mobility model, which argues that cultural capital does not mainly benefit high-SES children but, if possessed, benefits everyone.

\section{4 | Hypotheses}

Based on Bourdieu's theoretical arguments and on research that has extended these arguments, we now present a set of empirical hypotheses.

Our first two hypotheses arise from Bourdieu's argument that teachers misinterpret cultural capital as academic brilliance and reward it as such. Specifically, wehypothesize that children's cultural capital has a positive effect on teacher evaluations ( $\mathrm{H} 1$ a, i.e., signals affect teacher perceptions) and teacher evaluations have a positive effect on children's educational performance (H1b, i.e., signals lead to actions by teachers such as favoritism and preferential treatment). Both hypotheses are necessary for cultural capital to promote educational success via signals. Our empirical test of hypothesis $\mathrm{H} 1 \mathrm{a}$ and $\mathrm{H} 1 \mathrm{~b}$ builds on the assumptions that (1) children use their cultural capital in school and (2) teacher evaluations lead to manifest actions such a favoritism and preferential treatment.

Our second hypothesis is that cultural capital has a direct positive effect on educational performance $(\mathrm{H} 2)$. This hypothesis, which we base on our reading of Bourdieu and on a recent literature that makes this argument, captures that children who possess more cultural capital possess more analytical, creative, and social skills than children who possess less cultural capital. Our empirical test of this hypothesis builds on the assumption that our indicators of cultural capital capture variation in children's skills that affect educational performance.

Finally, we propose two hypotheses pertaining to contextual heterogeneity in the effect of cultural capital on educational performance. Our first contextual hypothesis is that the positive effect of cultural capital on teacher evaluations, and the positive effect of teacher evaluations on educational performance, is higher in high-SES schooling contexts than in low-SES ones (defined as contexts with, among other things, fewer poor students, better educated teachers and more gifted students; we present empirical indicators below). We label this hypothesis $\mathrm{H} 3$, and it captures the possibility that cultural capital-operating via signals rather than via skills-is an "inequality multiplier" that mainly benefits children in high-SES schooling contexts. Our second contextual hypothesis is that 
the direct positive effect of cultural capital-operating via skills rather than via signals-is higher in low-SES schooling contexts than in high-SES ones. We label this hypothesis $\mathrm{H} 4$, and it captures that the actual skills associated with cultural capital are in shorter supply in low-SES schooling contexts and, if possessed are more easily recognized and yield a higher return.

\section{3 | DATA}

We use data from two studies from the Early Childhood Longitudinal Program: the Kindergarten Class of 20102011 (ECLS-K:2011) and the Kindergarten Class of 1998-1999 (ECLS-K) (Tourangeau, Nord, Lê, Sorongon, \& Najarian, 2009; Tourangeau et al., 2017). We use these two datasets because, for nationally representative samples from the United States, each includes information on: (a) different aspects of children's cultural capital; (b) teacher evaluations of children's academic skills; (c) standardized test scores; (d) children's socioeconomic background; and (e) teacher, classroom, and school characteristics. The ECLS-K:2011 follows a sample of children from kindergarten to the second grade, while the ECLS-K follows another sample of children from kindergarten to the eighth grade. In this paper, we only use data from waves with repeated information on the dimensions listed above, which restricts the analysis to kindergarten and first grade in the ECLS-K:2011 and to first, third, and fifth grade in the ECLS-K.

ECLS-K initially sampled 21,409 children, but due to panel attrition and missing data on the specific variables that we use, we rely on a sample of 6,471 children who participated when they were in the first, third, and fifth grade. This sample is somewhat selective in that, compared to the full sample, respondents have higher SES, more children live in families with two biological parents, and there is a lower share of black, Hispanic, and Asian children (see online Appendix Table A1). However, substantive differences between samples are not large. In the fifth grade, the ECLS-K randomly assigned half of the participating children to have their mathematics skills evaluated by a teacher. This decision reduces the sample size to 3,005 for this variable, but since assignment was random, it does not induce sample selection. The ECLS-K includes an indicator of literacy skills for all children, which yields a sample size of 6,471 children for this variable. We use the sample weight provided with the ECLS-K to account for panel attrition and the complex survey design.

ECLS-K:2011 sampled 18,170 children in kindergarten. We restrict the analysis sample to children with valid responses on all key variables, which yields a sample of 6,149 children. As in the case of ECLS-K, the analysis sample has somewhat higher SES than the overall sample, more children live in families with two biological parents, and there are fewer minority students (see online Appendix Table A1). In this dataset we also use the sample weight provided with ECLS-K:2011.

Table 1 summarizes descriptive statistics for all variables included in the analysis, including the intra-class (i.e. within-child) correlation for all variables that vary over time.

\section{1 | Children's cultural capital}

Although it is difficult to measure a rich construct like cultural capital (Kingston, 2001; Lamont \& Lareau, 1988; Swidler, 1986; van de Werfhorst, 2010), in this paper we focus on three aspects of cultural capital that have been identified in previous research and that we can reasonably measure in the ECLS-K and the ECLS-K:2011. Specifically, we construct three summary scales that capture: (1) children's participation in performing arts classes; (2) their reading interest; and (3) their participation in athletics and clubs. Others have used the ECLS-K and ECLS-K:2011 to measure cultural capital in similar fashion (Bodovski, 2010; Bodovski \& Farkas, 2008; Cheadle, 2008, 2009; Covay \& Carbonaro, 2010; Dumais, 2006a, 2006b; Potter, Mashburn, \& Grissmer, 2013). We include 
TAB LE 1 Mean, standard deviation, and intra-class correlation coefficient (ICC)

\begin{tabular}{|c|c|c|c|c|c|c|}
\hline & \multicolumn{3}{|l|}{ ECLS-K } & \multicolumn{3}{|c|}{ ECLS-K:2011 } \\
\hline & Mean & Std. Dev. & ICC & Mean & Std. Dev. & ICC \\
\hline \multicolumn{7}{|l|}{ Educational performance } \\
\hline Reading test score & 0 & 1 & .74 & 0 & 1 & .79 \\
\hline Math test score & 0 & 1 & .79 & 0 & 1 & .81 \\
\hline \multicolumn{7}{|l|}{ Cultural capital } \\
\hline Performing arts & 0 & 1 & .46 & 0 & 1 & .47 \\
\hline Reading interest & 0 & 1 & .47 & 0 & 1 & .57 \\
\hline Athletics and clubs & 0 & 1 & .48 & 0 & 1 & .54 \\
\hline \multicolumn{7}{|l|}{ Teacher evaluation: } \\
\hline Evaluation of English skills & 0 & 1 & .55 & 0 & 1 & .60 \\
\hline Evaluation of math skills & 0 & 1 & .44 & 0 & 1 & .43 \\
\hline \multicolumn{7}{|l|}{ Controls } \\
\hline Socioeconomic status & 0 & 1 & .94 & 0 & 1 & .96 \\
\hline Number of siblings & 1.50 & 1.08 & .90 & 1.52 & 1.09 & .96 \\
\hline Two biological parents & .72 & .45 & .88 & .75 & .43 & .93 \\
\hline Female & .50 & .50 & & .49 & .50 & \\
\hline White & .69 & .46 & & .59 & .49 & \\
\hline Black & .09 & .28 & & .09 & .29 & \\
\hline Hispanic & .13 & .33 & & .20 & .40 & \\
\hline Asian & .04 & .21 & & .06 & .24 & \\
\hline Other ethnicity & .05 & .22 & & .06 & .23 & \\
\hline$N($ children $\times t)$ & 19,413 & & & 12,298 & & \\
\hline \multicolumn{7}{|l|}{ Teacher characteristics } \\
\hline Teacher has a Master's degree & $.18 / .18$ & $.38 / .38$ & $.20 / .20$ & .47 & .50 & .26 \\
\hline \multicolumn{7}{|l|}{ Teacher's parents have a } \\
\hline Master's degree & & & & .19 & .39 & .03 \\
\hline \multicolumn{7}{|l|}{ Classroom characteristics } \\
\hline Class size & $21.6 / 21.5$ & $4.87 / 4.65$ & $.41 / .44$ & 20.55 & 4.10 & .51 \\
\hline Gifted child in class & $.40 / .38$ & $.49 / .48$ & $.17 / .13$ & .15 & .35 & .19 \\
\hline $\begin{array}{l}\text { Proportion of gifted children in } \\
\text { class }\end{array}$ & $.05 / .05$ & $.10 / .09$ & $.20 / .10$ & .02 & .06 & .22 \\
\hline $\begin{array}{l}\text { Prop. of children reading below } \\
\text { average }\end{array}$ & & & & .19 & .14 & .20 \\
\hline $\begin{array}{l}\text { Prop. of children doing math below } \\
\text { average }\end{array}$ & & & .15 & .11 & .21 & \\
\hline Prop. of children being tardy & & & & .07 & .06 & .35 \\
\hline Prop. of children being absent & $.04 / .04$ & $.05 / .05$ & $.09 / .08$ & .04 & .04 & .19 \\
\hline Class behavior & $3.62 / 3.60$ & $.87 / .87$ & $.11 / .14$ & 3.48 & .86 & .13 \\
\hline \multicolumn{7}{|l|}{ School characteristics } \\
\hline School district poverty & & & & 18.63 & 11.03 & .97 \\
\hline
\end{tabular}


TABLE 1 (Continued)

\begin{tabular}{|c|c|c|c|c|c|c|}
\hline & \multicolumn{3}{|c|}{ ECLS-K } & \multicolumn{3}{|c|}{ ECLS-K:2011 } \\
\hline & Mean & Std. Dev. & ICC & Mean & Std. Dev. & ICC \\
\hline Private school & .24 & .43 & .96 & .13 & .34 & .93 \\
\hline Free lunch eligible & 31.55 & 25.99 & .80 & 38.03 & 30.68 & .83 \\
\hline$N($ children $\times t)$ & 19,413 & & & 12,298 & & \\
\hline
\end{tabular}

Note: The sample size differs for teacher, classroom, and school characteristics for reasons described in the data section. The cells with two numbers first provide the number for the English teacher and second the number for the mathematics teacher.

three different aspects of cultural capital because there is consensus that cultural capital pertains to more than familiarity with legitimate or "highbrow" culture (Lareau \& Weininger, 2003).

First, we use indictors of participation in performing arts classes to create a scale that captures familiarity with legitimate culture (see, e.g., DiMaggio, 1982; Downey, 1995; Dumais, 2006b; Roscigno \& Ainsworth-Darnell, 1999; Sullivan, 2001; Wildhagen, 2009). Our scale is a sum score of participation in: (1) dance lessons (only available in ECLS-K); (2) music lessons; (3) art classes; (4) organized performing arts programmes; and (5) drama classes (only available in ECLS-K:2011).

Second, we use two indicators of reading interest to create a scale that captures the literary climate in the home and how well the child has internalized this climate (de Graaf et al., 2000; Cheung \& Andersen, 2003; Sullivan, 2001). Our scale is a sum score based on: (1) how often the child reads outside of school; and (2) how many children's books the child has. Davis-Kean (2005) combines these two items in similar fashion.

Third, we use indicators of participation in clubs and athletics to create a scale that captures the child's skills in managing interactions in diverse institutional settings, including the ability to perform in public in front of adults and other social skills. As explained earlier, Lareau (2011) suggested that children learn skills from organized leisure activities, which subsequently affect their educational performance (Covay \& Carbonaro, 2010; Dumais, 2006a). Our scale is a sum score based on participation in: (1) organized clubs or recreational programs; and (2) organized athletics.

We construct each scale by adding the relevant items into a sum score and standardizing the sum score for each scale to have a mean of zero and a standard deviation of one within each grade. This means that for each grade level our indicators of cultural capital measure children's relative position within the distribution of cultural capital. The online Appendix Table A2 summarizes measures of reliability and correlations for the items used in the three scales. The table shows that statistical reliability is not particularly high for each scale; however, we use these scales because they are similar to how previous research has measured these aspects of cultural capital.

\section{2 | Teacher evaluations}

We use two empirical indicators from the ECLS-K and the ECLS-K:2011 to capture teachers' perceptions of children's academic ability. Our first indicator is the teacher's rating of the child's skills in oral and written expression, while our second indicator is the teacher's rating of the child's skills in math (mathematical problem solving and demonstration of mathematical reasoning). In kindergarten and first grade, the general classroom teacher rated both English and math skills. In third and fifth grade, the English and math teacher rated the child's skills in their respective subjects. This means that different teachers could have rated the child in the different grades. The ECLS-K provided teachers with examples to help them establish the level of difficulty of a particular item and for each grade level. In ECLS-K, teachers were asked to rate the child's skill, knowledge, or behavior using the following scale: 1 = "Poor," 2 = "Fair," 3 = "Good," 4 = "Very good," or 5 = "Outstanding." In the ECLS-K:2011, the scale was changed to: 1 = "Not yet," 2 = "Beginning," 3 = "Progress," 4 = "Intermediate," and 5 = "Proficient." The overall 
rating for each subject is the mean of the items pertaining to that subject. This mean rating is then standardized for each grade level to have a mean of zero and a standard deviation of one.

\subsection{Educational performance}

We use children's test scores in reading and math as empirical indicators of their educational performance. We measure performance in reading and math using standardized tests administrated by the National Center for Educational Statistics. We use the standardized test scores available in the ECLS-K and ECLS-K:2011 and rescale them within each grade level to have a mean of zero and a standard deviation of one. This means that for each grade level our dependent variables measure children's relative position within the distribution of educational performance.

\section{4 | Schooling contexts}

The ECLS-K and ECLS-K:2011 contain information on the SES characteristics of schools, teachers, and classrooms. Conditioning on valid responses for all contextual variables would reduce our sample size dramatically. For this reason, we use the valid responses within the analysis samples defined above. The online Appendix Table A3 reports relevant sample sizes.

Teachers: We use two variables as proxies for teachers' SES. Both the ECLS-K and ECLS-K:2011 include information on teachers' educational qualifications. We use a binary variable to capture whether the teacher has a Master's degree (or higher qualifications). In addition, the ECLS-K:2011 contains information on the educational attainment of the teacher's parents. We use this variable as a proxy for the teacher's SES background and include an indicator of whether any parent has graduate education (Master's Degree and beyond = 1, less than Master's Degree $=0$ ).

Classrooms: We are unable to measure SES at the classroom level directly. Instead, we use indicators of the academic and social environment in the class that is likely to reflect overall SES. To capture the academic environment in the classroom, we include indicators of: (1) class size; (2) whether there are any children classified as talented and gifted; (3) the proportion of children in the class classified as gifted and talented; (4) the proportion of children with reading skills below grade level (only available in ECLS-K:2011); and (5) the proportion of children with math skills below grade level (only available in ECLS-K:2011). To capture the social environment, we include indicators of: (1) the proportion of children being tardy on a typical week (only available in ECLS-K:2011); (2) the proportion of children being absent on a typical week; and (3) the teacher's rating of how well-behaved the children in the class are.

Schools: We use three indicators to capture school-level SES. The first indicator is a dummy variable indicating if the school is private or public (private $=1$; public $=0$ ). The second indicator measures the percentage of students in the school that is eligible for free lunch (a proxy for the share of low-income students in the context of the United States). The third indicator is the percentage of children aged 5-17 in the school district living in poverty (using the U.S. Census Bureau's definition of poverty). This variable is only available in the ECLS-K:2011.

\section{5 | Socioeconomic controls}

We also include a set of socioeconomic control variables. First, we include a summary indicator of family SES provided in the ECLS-K and the ECLS-K:2011. This continuous variable, which was constructed by the ECLS-K team and not by us, is derived from information on parents' occupational prestige (ranked according to the 1989 
General Social Survey prestige score), education and household income at the time of interview (Tourangeau et al., $2009,2017)$. We standardize this variable within each grade level to have a mean of zero and a standard deviation of one. Second, we include a binary variable indicating whether the child lives with both biological parents. Third, we include an indicator of number of siblings living in the household. Fourth, we include indicators of the child's sex $($ female $=1 ;$ male $=0)$ and race $($ black = 1 ; Hispanic $=1 ;$ Asian = 1; other = 1; white = 0). Table 1 shows means and standard deviations for the control variables.

\section{EMPIRICAL DESIGN}

In the empirical analysis, we wish to test five hypotheses concerning the effect of cultural capital on teacher evaluations $(\mathrm{H} 1 \mathrm{a})$; the effect of teacher evaluations on educational performance $(\mathrm{H} 1 \mathrm{~b})$; the direct effect of cultural capital on educational performance (H2); and whether the effect of cultural capital varies across schooling contexts, as measured by different school, teacher and classroom characteristics ( $\mathrm{H} 3$ and $\mathrm{H} 4)$. We write a panel regression model for children's educational performance:

$$
y_{i, t}=\alpha+\beta_{1} E_{i, t}+\beta_{2} \mathbf{C}_{i, t}+\beta_{2} \mathbf{X}_{i, t}+u_{i}+\varepsilon_{i, t}
$$

where $i$ denotes child $(i=1, \ldots, n)$ and $t$ denotes time period (i.e., grade). In this model $y$ is the child's test score in reading or math, $E$ is the teacher's evaluation of the child's English or math skills at time $t$, $\mathbf{C}$ is a vector that includes the three scales measuring different aspects of cultural capital, and $\mathbf{X}$ is a vector of control variables. Moreover, $\alpha$ is an overall constant, $u$ is a child-specific effect, and $\varepsilon$ is a random error term. The $\beta$ 's are regression coefficients. We exploit the panel data to estimate the model as a linear fixed effects (FE) model. The FE model uses within-child variation in all time-varying variables to difference out the child-specific fixed effect $u_{i}$, thereby controlling for all time-invariant, omitted characteristics that affect children's educational performance, cultural capital, and teacher evaluations. Stated differently, this model controls for omitted variables that are correlated with, but substantively different from, cultural capital (for example, children's baseline academic ability) whose omission would lead to biased estimates of the effect of cultural capital on educational performance (Gaddis, 2013; Jæger \& Breen, 2016).

We write a similar panel regression model for teacher evaluations:

$$
E_{i, t}=\phi+\gamma_{1} y_{i, t-1}+\gamma_{2} \mathbf{C}_{i, t}+\gamma_{3} \mathbf{X}_{i, t}+u_{i}+\xi_{i, t}
$$

where $E$ is the teacher's evaluation of the child's English or math skills in grade $t, y_{t-1}$ is the child's educational performance lagged one period, $\mathbf{C}$ and $\mathbf{X}$ are as described above, $u_{i}$ is a child-specific effect and $\xi$ is a random error term. As before, we use the panel data to estimate the model as an FE model. Our main objective is to isolate the signaling effect of cultural capital on teacher evaluations: that is, the effect of cultural capital that is unrelated to children's actual academic ability. To do this, in Equation 2 we control for the child's baseline academic ability (via the fixed effect) and her past educational performance in English or math (via $\left.y_{t-1}\right)$. We include past educational performance to take into account that, when evaluating a child's skills in the present, teachers possess information on the child's mastery of the curriculum in the past (Jæger \& Breen, 2016).

If cultural capital operates via signals, $\mathrm{H} 1$ a entails that $\gamma_{2}$ should be positive and statistically significant (cultural capital has a positive effect on teacher evaluations) and $\mathrm{H} 1 \mathrm{~b}$ entails that $\beta_{1}$ should be positive and statistically significant (teacher evaluations have a positive effect on educational achievement). If cultural capital operates via skills, $\mathrm{H} 2$ entails that $\beta_{2}$ should be positive and statistically significant (cultural capital has a direct effect on educational performance arising from skills associated with cultural capital). To test $\mathrm{H} 3$ and H4, we augment the FE models in Equations 1 and 2 by including the teacher, classroom, and school variables and by testing for 
interaction effects between these variables and the cultural capital variables. We test each interaction term individually to avoid conditioning on potential mediators or colliders. $\mathrm{H} 3$ implies that the positive effect of cultural capital on teacher evaluations $\left(\gamma_{2}\right)$, and the effect of teacher evaluations on educational performance $\left(\beta_{1}\right)$, should be stronger in high-SES schooling contexts (i.e., in schools with fewer poor students, better-educated teachers, more gifted students, and so on). H4 implies that the direct effect of cultural capital on educational performance $\left(\beta_{2}\right)$ should be stronger in low-SES schooling contexts.

\section{5 | RESULTS}

We present the main findings in three sections. First, we present results from FE regressions of children's educational performance on teacher evaluations and children's cultural capital. Second, we present results from FE regressions of teacher evaluations on children's cultural capital. These two sets of results enable us to assess if the effect of cultural capital on educational performance operates via teacher evaluations ( $\mathrm{H} 1 \mathrm{a}$ and $\mathrm{H} 1 \mathrm{~b})$ and/or if the effect is direct (H2). Third, we present results on whether the effect of cultural capital varies systematically with school, teacher, and classroom characteristics, as hypothesized in $\mathrm{H} 3$ and $\mathrm{H} 4$.

\section{1 | Cultural capital and educational performance}

Table 2 summarizes key results from regressions of children's standardized reading and math test scores on the cultural capital indicators, English and math teacher evaluations, and the control variables (see online Appendix Table A4 and A5 for full regression tables). For both datasets, we also present results from Ordinary Least Squares (OLS) regressions to compare our results with those found in previous research (most of which uses OLS regression). Finally, we run models with and without teacher evaluations to assess the extent to which teacher evaluations mediate any direct effect of the cultural capital indicators on educational performance.

OLS regression models that do not include teacher evaluations (Models 1 and 5) show that all three aspects of cultural capital-participation in performing arts, reading interest, and participation in athletics and clubs-are positively associated with educational performance. These baseline results are in line with previous research (e.g., Bodovski, 2010; Bodovski \& Farkas, 2008; DiMaggio, 1982; Sullivan, 2001). When we add English and math teacher evaluations to the models (cf. Models 2 and 6), we find that teacher evaluations mediate some of the associations between the cultural capital indicators and educational performance.

When we rerun the models as FE models, and thereby control for omitted child characteristics that are correlated with cultural capital and educational performance, we get different results. In the FE model for children's reading test scores, and for both datasets, we find that, both before (Model 3) and after (Model 4) controlling for teacher evaluations, reading interest is the only cultural capital indicator that has a positive direct effect on reading test scores. In Model 4, we estimate that increasing reading interest by one standard deviation increases reading test scores by .046 standard deviations in the ECLS-K:2011 and .061 standard deviations in the ECLS-K (both $p<.001$ ). Results are similar in the FE models for math, in which we find that reading interest is the only cultural capital indicator that affects test scores in the ECLS-K (models 7 and 8), but not in the ECLS-K:2011.,2 An explanation for these different results may be that the skills associated with reading interest are less important for math performance in the early school years (kindergarten and first grade) than in the middle school years (third and fifth grade). ${ }^{3}$

Our conclusion from the first step of the analysis is that one aspect of cultural capital, reading interest, has a direct positive effect on educational performance. Given that our models control for baseline academic ability and other omitted child characteristics, we interpret this result as consistent with $\mathrm{H} 2$ stating that cultural capital fosters skills in children, for example analytical and creative skills, that help them master the curriculum (as 


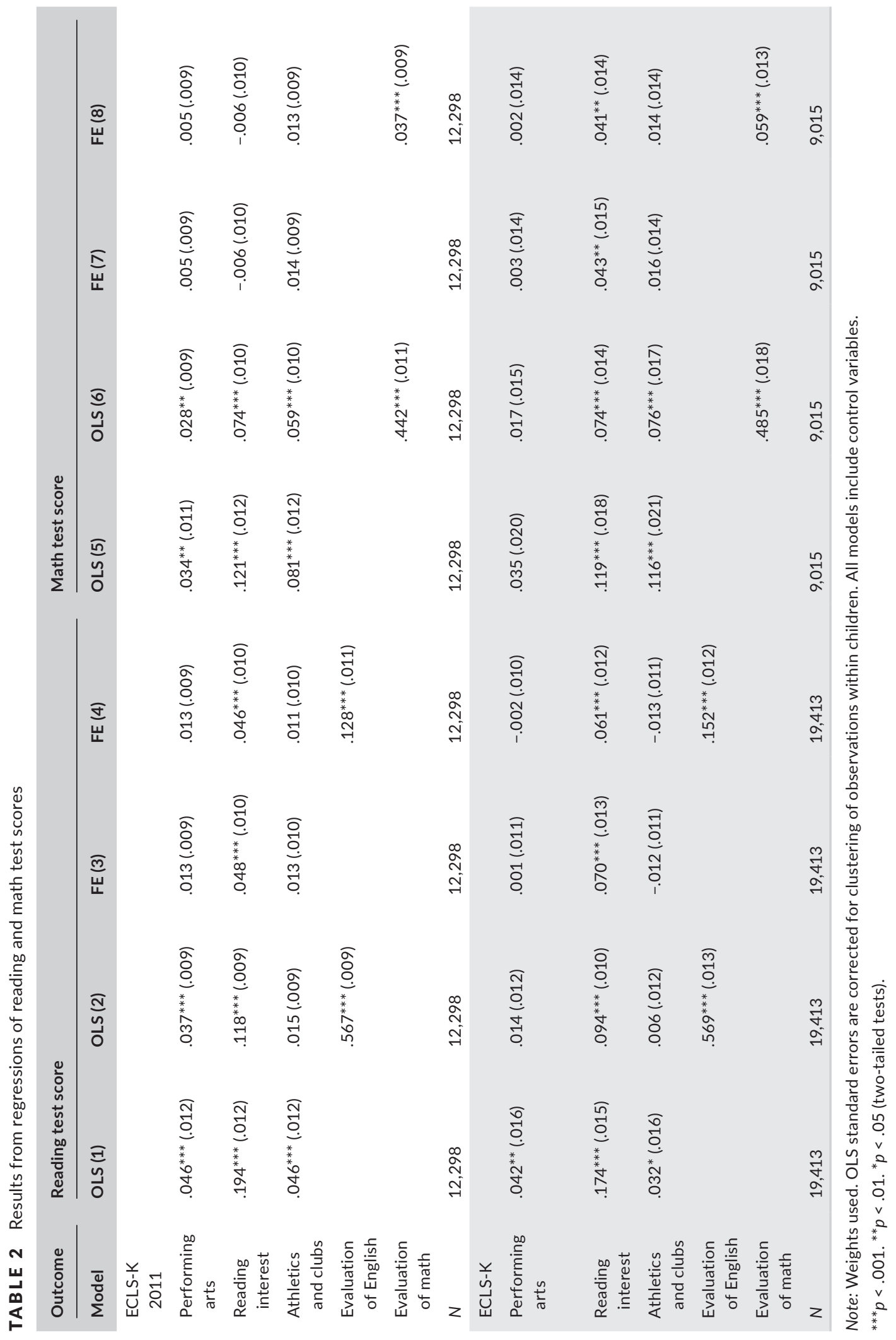


witnessed in higher reading and math test scores). As noted earlier, this interpretation rests on the assumption that our reading interest scale is a proxy for skills associated with cultural capital. Although we cannot test this assumption, previous research applies a similar interpretation of the positive association between reading and educational performance (e.g., de Graaf et al., 2000; Sullivan, 2007). Moreover, in both datasets we find that teacher evaluations consistently have a positive effect on reading and math test scores. These results support $\mathrm{H} 1 \mathrm{~b}$ claiming that teacher evaluations affect educational performance. As we have argued above, empirical support for $\mathrm{H} 1 \mathrm{~b}$ is a necessary but not a sufficient condition for the hypothesis that cultural capital operates via signals to hold. The second condition that must also hold is that cultural capital affects teacher evaluations; that is, $\mathrm{H} 1 \mathrm{a}$. We now address this question.

\subsection{Cultural capital and teacher evaluations}

Table 3 summarizes results from OLS and FE regressions of teacher evaluations of children's English and math skills on children's cultural capital, past educational performance and controls (see online Appendix Table A6 and A7 for full regression results). The hypothesis that we wish to test is that cultural capital has a positive effect on teacher evaluations because teachers misinterpret cultural capital as academic brilliance (H1a).

The OLS models for teacher evaluations of English skills (Models 9 and 10) show that, even after we control for past educational performance, several of our indicators of cultural capital are positively associated with teachers' evaluations of children's English skills. In the OLS models for teacher evaluations of math skills, reading interest is the only indicator of cultural capital that remains statistically significant after we control for past performance.

Results from the FE models provide little support for H1a. Before controlling for children's past educational performance (Models 11 and 15), we find that only one indicator of cultural capital, reading interest, has a statistically significant and positive effect on teacher evaluation of children's English skills in the ECLS-K (but not in the ECLS-K:2011). After we control for children's past educational performance, none of the cultural capital variables are significant. ${ }^{4}$ Our substantive interpretation of these results is that, at least in the context of the United States, the three aspects of cultural capital that we study do not appear to operate via signals of academic brilliance. Below, we analyse if a signaling effect of cultural capital might still exist in high- and low-SES schooling contexts, respectively.

\section{3 | Schooling contexts}

Our empirical analysis shows that one of our three indicators of cultural capital, reading interest, has a direct positive effect on educational performance $(\mathrm{H} 2)$ but does not appear to have any indirect effect operating via teacher evaluations ( $\mathrm{H} 1 \mathrm{a}, \mathrm{H} 1 \mathrm{~b})$. However, this average effect could mask important contextual differences if cultural capital converts more easily into favorable teacher evaluations or recognizable skills in some SES schooling contexts than in others. We use the rich data on teachers, classrooms, and schools in the ECLS-K surveys to test H3 and $\mathrm{H} 4$. These hypotheses state that the effect of cultural capital on teacher evaluations is higher in high-SES schooling contexts than in low-SES ones (H3), and the direct effect of cultural capital on educational performance is higher in low-SES schooling contexts than in high-SES ones (H4). To test these hypotheses, we estimate FE regressions of teacher evaluations and educational performance that include main effects of the teacher, classroom, and school variables listed in Table 1 and interaction effects between these variables and the cultural capital variables. We summarize results in the online Appendix Table A8-A10.

To our surprise, we find no evidence that the effect of any of our cultural capital variables on teacher evaluations and on children's educational performance varies systematically across high- and low-SES schooling contexts. Of a total of 252 interaction terms tested in the FE models, none are statistically significant after we adjust 


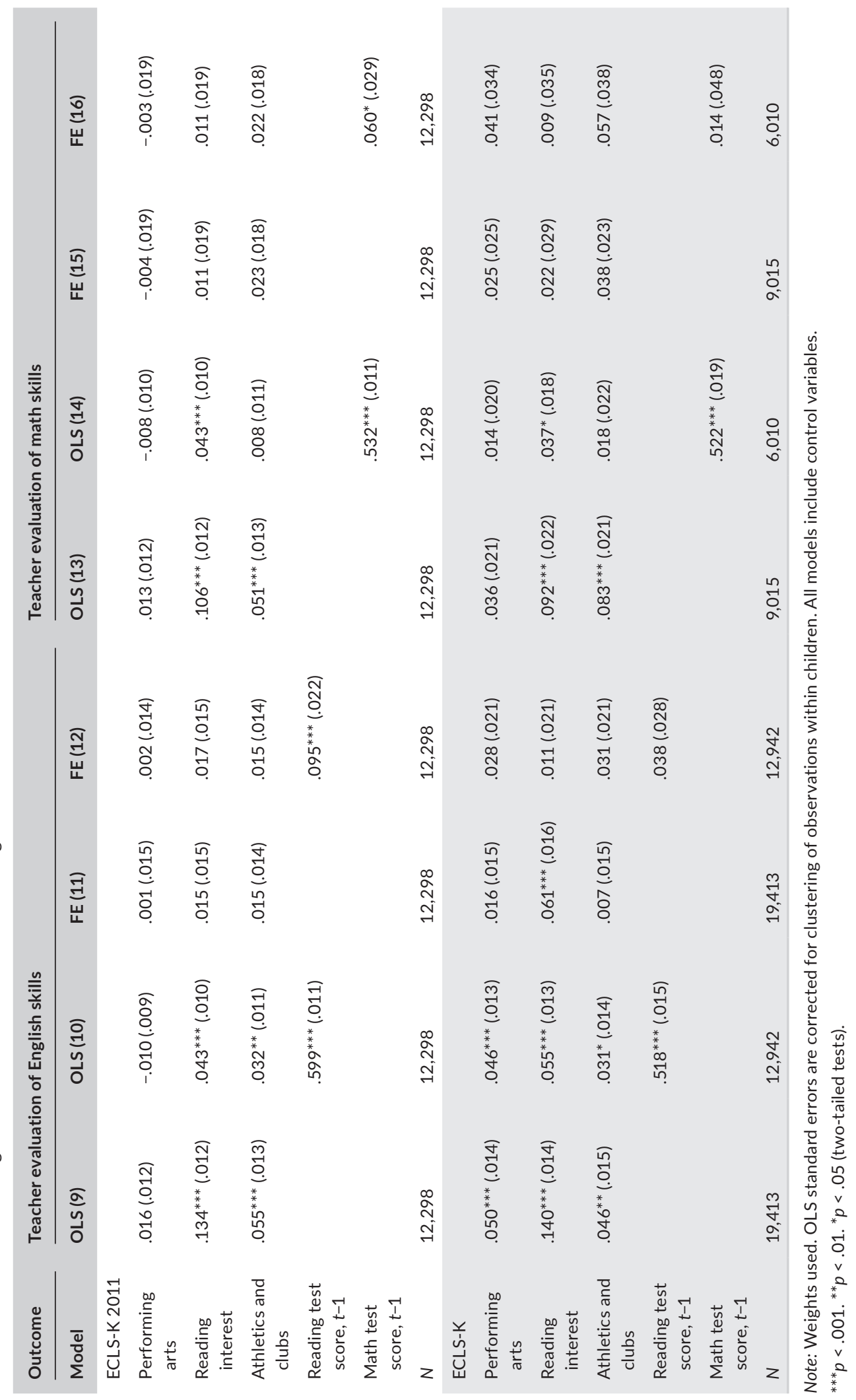


for the false discovery rate associated with running a large number of tests (we use the Benjamini-Hochberg procedure to do this; McDonald, 2014). This result is surprising given the very large variation in SES and schooling contexts that exists in the United States (Hyman, 2017). We interpret this result to suggest that, at least in the United States and in the data that we analyse, there is no evidence that the link between the three aspects of cultural capital and teacher evaluations, and the link between these aspects of cultural capital and educational performance, depend on the SES of the schooling context. We note that our FE models provide a strict test of contextual heterogeneity because they rely exclusively on within-unit (teacher, classroom, school) variation in the contextual variables and thus disregard all cross-sectional variation.

\section{6 | DISCUSSION}

In this paper, we test two mechanisms through which cultural capital might affect educational success. We draw on Bourdieu and on other research on cultural capital to argue that cultural capital might affect educational success by: (a) sending signals of academic brilliance to teachers who in turn form upwardly biased perceptions of children's academic ability; and (b) fostering actual skills in children that directly enhance educational performance. Moreover, we hypothesize that the effect of cultural capital might vary across high- and low-SES schooling contexts due to differences in the ways in which cultural capital is recognized and rewarded.

We analyse rich panel data from the United States and use a robust fixed effects design to control for omitted characteristics that correlate with cultural capital and educational performance. Overall, our empirical results suggest that cultural capital operates via skills rather than via signals of academic ability. Specifically, we find that, net of omitted characteristics and actual mastery of the curriculum (as measured by past performance in reading and math), children's participation in performing arts, athletics and clubs, and their reading interest, have no effect on teachers' evaluations of their academic skills. Instead, our results indicate that one aspect of cultural capital, children's reading interest, has a direct positive effect on reading and math test scores. This result is consistent with the idea that the literary environment in the family cultivates skills in children-for example, a complex vocabulary, creativity, and cultural knowledge-that enhance educational performance (de Graaf et al., 2000; Kaufman \& Gabler, 2004; Lareau \& Weininger, 2003, Sullivan, 2007). The result is also consistent with previous findings that, among different dimensions of cultural capital, reading is the dimension that is most strongly correlated with educational performance (Gaddis, 2013). Finally, and to our surprise given the large variation in schooling contexts that exists in the United States, we find no evidence that the effect of the three aspects of cultural capital on teacher evaluations and educational performance differs across teacher, classroom, and school characteristics that capture high- and low-SES schooling contexts, respectively.

We conclude the paper by highlighting three limitations in our analysis and discussing some avenues for future research. First, when operationalizing cultural capital we draw on measures that previous studies have shown to be positively correlated with educational performance (e.g., Covay \& Carbonaro, 2010; DiMaggio, 1982; Gaddis, 2013; de Graaf, 1986). However, it is unlikely that our indicators of cultural capital capture all relevant aspects of cultural capital and the ways in which cultural capital affects educational success. For example, qualitative research by Calarco $(2011,2014)$ shows that children's propensity to seek help from teachers varies by SES background, and furthermore that these socially stratified help-seeking strategies lead to differences in how teachers perceive and treat children. Unfortunately, we are unable to address these interactional aspects of cultural capital, and we are not aware of any existing datasets that would allow us to address them. Future quantitative data collections should include data on interactional aspects of cultural capital.

Second, Bourdieu and others argued that embodied cultural capital is the key mechanism through which cultural capital enhances educational success. This means that we should observe how students "do" their cultural capital, not only which cultural activities they participate in. We are limited by empirical indicators of cultural participation, which means that we assume that these indicators are proxies for physical manifestations of, or skills 
associated with, cultural capital. This is not ideal. However, one redeeming feature of our analysis compared to other quantitative research is that we observe teachers' subjective assessments of students, which logically must depend on how students "do" their cultural capital in school.

Third, while our data include indicators of teachers' perceptions of children, they do not include indicators of the actions that teachers take based on these perceptions. This means that we assume that teachers favor and give preferential treatment to children whom they regard as more academically gifted. Although we find that teacher evaluations have a positive effect on educational performance (which suggest that teachers' perceptions lead them to act in ways that affects children's performance), we would much prefer to measure how teachers treat children. For example, we would like to measure the amount of time teachers directly interact with children or the length of written responses on assignments.

In addition to highlighting empirical limitations, we would also like to discuss the consequences of our findings for future research on cultural capital. Our main empirical result is that some aspects of cultural capital affects educational success, but that the mechanism through which cultural capital operates is via skills rather than via signals of academic brilliance. This result challenges the traditional interpretation of cultural capital as an essentially unproductive "con capital" whose purpose is to signal familiarity with arbitrarily defined high-status culture (Ganzeboom, 1982). Moreover, the finding that children are unable to convert their cultural capital into favorable teacher perceptions-even in high-SES schooling contexts in which teachers might be particularly receptive to high-status culture-support this argument. Altogether, our results are in line with a recent literature arguing that cultural capital, transmitted from parents to children and fostered via participation in diverse activities, is a set of skills that enhances children's educational performance (Kaufman \& Gabler, 2004; Kisida et al., 2014; Sullivan, 2007). If true, this interpretation of cultural capital as a set of skills that apply in most settings might also explain why we find no contextual heterogeneity in the effect of cultural capital on educational performance and teacher perceptions. Still, more work is needed to unpack the different ways in which cultural capital enhances educational performance in different settings.

\section{ACKNOWLEDGMENT}

We have presented earlier versions of this paper at the UNITRAN workshop at the University of Copenhagen, June 2015, the RC28 Meeting at the University of Pennsylvania, August 2015, the Population Association of America Annual Meeting, March 2016, the RC28 Meeting at the National University of Singapore, May 2016, the American Sociological Association Annual Meeting, August 2016, and the Family, Inequality and Demography Workshop at the University of Michigan, January 2016. We thank participants at these conferences and workshops for valuable feedback. The research leading to the results presented in this article has received funding from the European Research Council under the European Union's Seventh Framework Programme [FP/2007-2013]/ ERC grant 312906.

\section{DATA AVAILABILITY STATEMENT}

The data that support the findings of this study are openly available from the National Center for Education Statistics, U.S. Department of Education, at https://nces.ed.gov/ecls/dataproducts.asp.

\section{ORCID}

Asta Breinholt iD https://orcid.org/0000-0002-4706-8470

Mads Meier Jæger (iD https://orcid.org/0000-0003-3666-8398

\section{NOTES}

${ }^{1}$ It may be that children who do better in school find more pleasure in reading. In supplementary analyses, we have addressed potential reverse causality by using additional data from the ECLS-K:2011 in which we observe children's reading 
test scores around 6 months after we observe their reading interest (instead of measuring both at time $t$ ). Results from FE models using these data are identical to the ones we report in Table II (results are available upon request).

2 In supplementary analyses, we have split up the reading interest scale into its constituent components to assess if one item drives our results. Results show that the item capturing how often the child reads outside of school drives most of the positive effect of reading interest on educational performance (results are available upon request). However, in some cases, and in particular in the FE regressions of reading test scores in the ECLS-K, we find that the number of books also has an independent effect. Based on these results, we use the combined scale in the main analysis.

${ }^{3}$ Since the two ECLS-K surveys were collected 12 years apart (and the 2011 wave was collected in the aftermath of the financial crisis), we have analyzed if children's participation in performing arts, athletics and clubs, as well as the SES gradients in patterns of participation, are different in each wave. We find little evidence that this is the case (further results are available upon request).

${ }^{4}$ One might argue that our FE models, which also include the child's past educational performance, are too conservative. However, even in the FE models in which we do not control for past educational performance, only one cultural capital variable, reading interest, has a statistically significant and positive effect on teacher evaluation of literacy skills, and only in one dataset (model 11, ECLS-K). Thus, support for H1a is limited.

\section{REFERENCES}

Andersen, I. G., \& Jæger, M. M. (2015). Cultural capital in context: Heterogeneous returns to cultural capital across schooling environments. Social Science Research, 50, 177-188.

Bloome, D. (2015). Income inequality and intergenerational income mobility in the United States. Social Forces, 93(3), 1047-1080.

Bodovski, K. (2010). Parental practices and educational achievement: Social class, race, and habitus. British Journal of Sociology of Education, 31(2), 139-156.

Bodovski, K., \& Farkas, G. (2008). "Concerted cultivation" and unequal achievement in elementary school. Social Science Research, 37(3), 903-919.

Bourdieu, P. (1984). Distinction: A social critique of the judgement of taste. London, UK: Routledge \& Kegan Paul.

Bourdieu, P. (1996). The state nobility. Palo Alto, CA: Stanford University Press.

Bourdieu, P. (2006 [1986]). The forms of capital. In H. Lauder, P. Brown, J.-A. Dillabough, \& A. H. Halsey (eds.), Education, globalization \& social change (pp. 105-118). Oxford: Oxford University Press.

Bourdieu, P., \& Passeron, J.-C. (1977). Reproduction in education, society and culture. London, UK: Sage Publications.

Calarco, J. M. (2011). I need help! Social class and children's help-seeking in elementary school. American Sociological Review, 76(6), 862-882.

Calarco, J. M. (2014). Coached for the classroom: Parents cultural transmission and children's reproduction of educational inequalities. American Sociological Review, 79(5), 1015-1037.

Cheadle, J. E. (2008). Educational investment, family context, and children's math and reading growth from kindergarten through the third grade. Sociology of Education, 81(1), 1-31.

Cheadle, J. E. (2009). Parent educational investment and children's general knowledge development. Social Science Research, 38(2), 477-491.

Cheung, S. Y., \& Andersen, R. (2003). Time to read: Family resources and educational outcomes in Britain. Journal of Comparative Family Studies, 34(3), 413-433.

Covay, E., \& Carbonaro, W. (2010). After the bell: Participation in extracurricular activities, classroom behavior, and academic achievement. Sociology of Education, 83(1), 20-45.

Davies, S., \& Rizk, J. (2017). The three generations of cultural capital research: A narrative review. Review of Educational Research, 88(3), 331-365.

Davis-Kean, P. E. (2005). The influence of parent education and family income on child achievement: The indirect role of parental expectations and the home environment. Journal of Family Psychology, 19(2), 294-304.

de Graaf, P. M. (1986). The impact of financial and cultural resources on educational attainment in the Netherlands. Sociology of Education, 59(4), 237-246.

de Graaf, N. D., de Graaf, P. M., \& Kraaykamp, G. (2000, April). Parental cultural capital and educational attainment in the Netherlands: A refinement of the cultural capital perspective. Sociology of Education, 73, 92-111.

DiMaggio, P. (1982). Cultural capital and school success: The impact of status culture participation on the grades of U.S. high school students. American Sociological Review, 47(2), 189-201.

Downey, D. B. (1995). When bigger is not better: Family size, parental resources, and children's educational performance. American Sociological Review, 60(5), 746-761.

Dumais, S. A. (2006a). Elementary school students' extracurricular activities: The effects of participation on achievement and teachers' evaluations. Sociological Spectrum, 26(2), 117-147. 
Dumais, S. A. (2006b). Early childhood cultural capital, parental habitus, and teachers' perceptions. Poetics, 34(2), 83-107.

Farkas, G., Sheehan, D., Grobe, R. P., \& Shuan, Y. (1990). Cultural resources and school success: Gender, ethnicity, and poverty groups within an urban school district. American Sociological Review, 55(1), 127-142.

Farkas, G. (2018). Families, schooling, and cultural capital. In B. Schneider \& G. Saw (Eds.), Handbook of the sociology of education in the 21st century (pp. 3-38). Cham: Springer.

Freedman, D. A. (1991). Statistical models and shoe leather. Sociological Methodology, 21(1), 291-313.

Gaddis, S. M. (2013). The influence of habitus in the relationship between cultural capital and academic achievement. Social Science Research, 42(1), 1-13.

Ganzeboom, H. (1982). 'Explaining differential participation in high-cultural activities: A confrontation of information-processing and status seeking theories.In W. Raub (Ed.), Theoretical models and empirical analyses (pp. 186-205). Utrecht, the Netherlands: E.S.-Publications.

Hyman, J. (2017). Does money matter in the long run? Effects of school spending on educational attainment. American Economic Journal: Economic Policy, 9(4), 256-280.

Jæger, M. M., \& Breen, R. (2016). A dynamic model of cultural reproduction. American Journal of Sociology, 121(4), 1079-1115.

Kahn, S. (2012). Privilege. The making of an adolescent elite at St. Paul's school. Princeton, NJ: Princeton University Press.

Kalmijn, M., \& Kraaykamp, G. (1996). Race, Cultural Capital, and Schooling: An Analysis of Trends in the United States. Sociology of Education, 69(1), 22-34.

Kaufman, J., \& Gabler, J. (2004). Cultural capital and the extracurricular activities of girls and boys in the college attainment process. Poetics, 32(2), 145-168.

Kingston, P. W. (2001). The unfulfilled promise of cultural capital theory. Sociology of Education, 74, 88-99.

Kisida, B., Greene, J. P., \& Bowen, D. H. (2014). Creating cultural consumers: The dynamics of cultural capital acquisition. Sociology of Education, 87(4), 281-295.

Kozlowski, K. P. (2015). Culture or teacher bias? Racial and ethnic variation in student-teacher effort assessment match/ mismatch. Race and Social Problems, 7(1), 43-59.

Lamont, M., \& Lareau, A. (1988). Cultural capital: Allusions, gaps and glissandos in recent theoretical developments. Sociological Theory, 6(2), 153-168.

Lareau, A. (2011). Unequal childhoods: Class, race, and family life. With an update a decade later. Oakland, CA: University of California Press.

Lareau, A., \& Weininger, E. B. (2003). Cultural capital in educational research: A critical assessment. Theory \& Society, 32(5/6), 567-606.

Leopold, L., \& Shavit, Y. (2013). Cultural capital does not travel well: Immigrants, natives and achievement in israeli schools. European Sociological Review, 29(3), 450-463.

McDonald, J. H. (2014). Handbook of biological statistics (3rd ed.). Baltimore, MD: Sparky House Publishing.

National Center for Educational Statistics. (2009). The Early Childhood Longitudinal Study, Kindergarten Class of 1998-99 (ECLS-K). National Center for Educational Statistics, Institute of Education Sciences, U.S. Department of Education; ECLS-K: Kindergarten-Eight Grade Public-use File.

National Center for Educational Statistics. (2017). The Early Childhood Longitudinal Study, Kindergarten Class of 201011 (ECLS-K:2011). National Center for Educational Statistics, Institute of Education Sciences, U.S. Department of Education; ECLS-K:2011 Kindergarten-Second Grade Public-use File.

Potter, D., Mashburn, A., \& Grissmer, D. (2013). The family, neuroscience, and academic skills: An interdisciplinary account of social class gaps in children's test scores. Social Science Research, 42(2), 446-464.

Roscigno, V. J., \& Ainsworth-Darnell, J. W. (1999). Race, cultural capital, and educational resources: Persistent inequalities and achievement returns. Sociology of Education, 72(3), 158-178.

Sullivan, A. (2001). Cultural capital and educational attainment. Sociology, 35(4), 893-912.

Sullivan, A. (2007). Cultural capital, cultural knowledge and ability. Sociological Research Online, 12(6), 1-14.

Swidler, A. (1986). Culture in action: Symbols and strategies. American Sociological Review, 51, 273-286.

Takei, Y., Johnson, M. P., \& Clark, M. E. (1998). Academic achievement and impression management as factors in the grading of white junior high pupils. Sociological Perspectives, 41(1), 27-48.

Tourangeau, K., Nord, C., Lê, T., Sorongon, A. G., \& Najarian, M. (2009). Early Childhood Longitudinal Study, Kindergarten Class of 1998-99 (ECLS-K). Combined User's Manual for the ECLS-K Eighth-Grade and K-8 Full Sample Data Files and Electronic Codebooks (NCES 2009-004). Washington, DC: National Center for Education Statistics, Institute of Education Sciences, U.S. Department of Education.

Tourangeau, K., Nord, C., Lê, T., Wallner-Allen, K., Vaden-Kiernan, N., Blaker, L., \& Najarian, M. (2017). Early Childhood Longitudinal Study, Kindergarten Class of 2010-11 (ECLS-K:2011) User's Manual for the ECLS-K:2011 KindergartenSecond Grade Data File and Electronic Codebook, Public Version (NCES 2017-285). Washington, DC: U.S. Department of Education, National Center for Education Statistics. 
van de Werfhorst, H. G. (2010). Cultural capital: Strengths, weaknesses and two advancements. British Journal of Sociology of Education, 31(2), 157-169.

Wildhagen, T. (2009). Why does cultural capital matter for high school academic performance? An empirical assessment of teacher-selection and self-selection mechanisms as explanations of the cultural capital effect. Sociological Quarterly, 50(1), 173-200.

\section{SUPPORTING INFORMATION}

Additional supporting information may be found online in the Supporting Information section.

How to cite this article: Breinholt A, Jæger MM. How does cultural capital affect educational performance: Signals or skills?. Br J Sociol. 2020;71:28-46. https://doi.org/10.1111/bjos.12711 